\title{
EXPERIÊNCIA URBANA E DIFERENÇA GERACIONAL NA FORMAÇÃO DA CULTURA POPULAR JAPONESA
}

Ernani Oda

Resumo: A popularidade da cultura popular japonesa (e.g. anime, manga) tem sido acompanhada de discursos essencialistas que retratam este fenômeno como reflexo de atributos supostamente imutáveis que teriam sido herdados desde tempos remotos. Embora este tipo de tese venha sendo corretamente criticada por diversos teóricos sociais, estes autores nem sempre oferecem esquemas teóricos alternativos. O objetivo deste trabalho é identificar elementos conceituais que contribuam para a formação de uma alternativa neste sentido. A partir da análise de uma corrente influente da sociologia da cultura no Japão, dois conceitos serão especialmente enfatizados: urbanização e diferença geracional. Estes dois conceitos permitem compreender de maneira mais clara a diversidade e a historicidade das condições sociais por trás da formação e transformação de diversos aspectos da cultura popular no Japão.

Palavras-chave: Japão, cultura japonesa, cultura popular, urbanização, geração

Abstract: With the rising popularity of Japanese popular culture (e.g. anime, manga), there has also been an increase in essentialist discourses describing this as the manifestation of supposedly immutable features of Japanese culture. Although several social theorists have rightly criticized this line of argument, they often fail to provide a theoretically clear alternative framework. The aim of this study is to identify conceptual elements that might help us develop such a framework. Based on the work of influential sociologists of culture in Japan, I argue that two concepts in particular deserve special attention: urbanization and generational difference. These two concepts allow us to understand more clearly the diversity and the historicity of the social conditions giving rise to popular culture in Japan today.

Keywords: Japan, Japanese culture, popular culture, urbanization, generation

\section{Introdução}

A presença da cultura popular japonesa no cenário internacional tem se tornado cada vez mais visível nas últimas décadas. Nos mais diversos países é possível apontar

1 Possui graduação em Direito pela Universidade de São Paulo (2000), mestrado em Sociologia pela Kyoto University (2008) e doutorado em Sociologia pela Kyoto University (2013). A pesquisa para a elaboração deste artigo foi realizada com apoio da Coordenação de Aperfeiçoamento de Pessoal de Nível Superior (Capes). 
a crescente popularidade de certos gêneros como o manga (histórias em quadrinhos), o anime (desenhos animados) e jogos de videogame produzidos no Japão (Watanabe; McConnell, 2008). Este fenômeno tem sido tão notável a ponto de o próprio governo japonês passar a adotar oficialmente a promoção da cultura popular. Com o slogan de "Cool Japan", esta iniciativa tem usado desenhos e jogos eletrônicos como instrumentos de diplomacia cultural para aumentar a projeção internacional do Japão, tendo em vista o relativo declínio da imagem japonesa desde meados da década de 1990, decorrente do enfraquecimento de sua economia (Lam, 2007).

Naturalmente, o interesse acadêmico por esses aspectos da cultura popular japonesa vem aumentando na mesma proporção. Mais do que o conteúdo das obras e jogos em si, muitos pesquisadores vêm debatendo intensamente o seu significado social e político, tanto dentro como fora do Japão. Não surpreende, por isso, que muitos estudos recentes que se propõem a discutir a sociedade japonesa contemporânea de maneira mais abrangente incluam também análises específicas sobre a cultura popular (e.g. Harootunian; Yoda, 2006; Bestor; Bestor; Yamagata, 2011; Kawano; Roberts; Long, 2014).

No entanto, surgem aqui algumas dificuldades. Certas interpretações influentes tendem a descrever o fenômeno da cultura popular em termos bastante essencialistas, como reflexo de uma suposta matriz cultural japonesa cujas características relativamente imutáveis teriam sido transmitidas desde tempos antigos. Não é incomum, por exemplo, encontrar teses que identificam diferentes aspectos das modas e gostos atuais como adaptações de práticas existentes no Japão desde o período Edo (1600-1868): o anime teria sua origem no teatro kabuki, e a atual devoção extrema dos fãs aficionados por anime, manga e jogos de videogame - os chamados otaku - seria herança do senso estético das classes comerciais que viviam na cidade de Edo, com suas regras e convenções para apreciar o teatro e as artes da época (Okuno, 2014; 2015).

Evidentemente, este tipo de interpretação tem sido alvo de várias críticas. Salientase, em primeiro lugar, que ela não costuma oferecer muito mais do que analogias superficiais e pontuais para traçar seus paralelos entre a cultura popular atual e os hábitos de épocas anteriores. Mas mais importante, ao retratar as práticas atuais como mera reprodução de padrões culturais antigos, esta tese ignora a enorme complexidade de conflitos, negociações e transformações vividas na sociedade japonesa desde o período Edo até os dias atuais. Justamente por negligenciar a mudança das condições sociais concretas por trás das práticas culturais, tanto do ponto de vista de sua produção como de sua recepção, muitas das generalizações que costumam ser feitas sobre a cultura popular atual acabam se tornando arbitrárias (Iwabuchi, 2002; 2010; Miller, 2011).

Creio que esta crítica é correta e que de fato a atenção para a historicidade das condições particulares das práticas culturais são uma tarefa central. Mas os críticos nem sempre deixam claro como fazer isso. Como podemos escapar das armadilhas do essencialismo e efetivamente tratar do problema de forma coerente? O universo de condições sociais que poderíamos em princípio associar à formação da cultura popular 
japonesa é imenso, e seria claramente impossível analisar todos eles. É necessário, portanto, selecionar, ainda que provisoriamente, certos aspectos em detrimento de outros, e para isso precisamos de conceitos que nos ajudem a orientar nosso foco analítico. Mas os críticos do essencialismo muitas vezes têm dificuldade em explicar que conceitos seriam esses.

Por isso, meu objetivo neste trabalho é discutir uma corrente teórica que oferece alternativas para esse problema. Trata-se de um grupo de autores ligados à teoria da cultura no Japão, cujas ideias se baseiam principalmente na obra do sociólogo Munesuke Mita. Embora não se trate de um debate voltado exclusivamente para a questão da cultura popular, esta tem um papel central em sua formulação, de modo que os conceitos desenvolvidos por Mita e seus seguidores têm relevância direta para a discussão desse fenômeno.

Minha leitura desses autores é necessariamente seletiva. Meu propósito não é oferecer uma sinopse fiel de seus textos, mas extrair deles elementos que possam ajudar na formulação de um esquema teórico que permita explicar melhor as condições sociais por trás da cultura popular japonesa. Obviamente, não seria possível aqui examinar detalhadamente todos os estudos dos autores ligados a essa corrente. Portanto, irei concentrar-me apenas nos conceitos que, em minha leitura, são mais representativos. É possível já adiantar aqui que dois deles são particularmente importantes: urbanização e diferença geracional. A discussão nas seções seguintes irá tomar esses dois conceitos como ponto de referência, destacando seu potencial analítico. No entanto, como seria de esperar, este esquema teórico têm também suas limitações, algumas bastante sérias. Concluo o trabalho, por isso, com uma reflexão sobre esses problemas.

\section{Cultura "popular" em que sentido?}

O cerne do esquema teórico que tentarei articular pode ser encontrado no livro Kindai Nihon no Shinjô no Rekishi: Ryûkôka no Shakai Shinrishi, originalmente publicado por Munesuke Mita em 1967 e provavelmente seu trabalho mais conhecido. Trata-se de um minucioso estudo sobre o conteúdo das letras de canções que fizeram sucesso no Japão desde o período Meiji (1868-1912) até a década de 1960. Embora seja um trabalho relativamente antigo que não faz qualquer menção aos gêneros de cultura popular hoje mais em evidência como manga ou anime, os conceitos elaborados por Mita para compreender o universo das canções populares oferece um quadro de referência que, como veremos, pode ajudar a esclarecer muitas questões relacionadas ao contexto atual.

Antes de examinar o que ele tem a dizer sobre essas canções, porém, convém esclarecer como Mita entende o próprio conceito mais amplo de cultura "popular", do qual as canções são no fundo apenas um aspecto particular. Em que sentido seria possível qualificar certas obras como sendo populares? A estratégia de Mita é caracterizar o popular por associação a "povo", um termo que por sua vez se define em oposição à noção de "elite", seja no sentido político, econômico ou social. A palavra que Mita usa para designar o povo neste caso é minshu, em contraposição a eriito. O povo ou 
minshu, portanto, seria aquela camada de pessoas que está fora da esfera do governo, dos grandes empreendimentos econômicos e das tradicionais famílias aristocráticas (Mita, 2012b, p. 67-68).

Mas de que forma surgiria uma cultura própria ao povo neste sentido? A resposta de Mita aqui é significativa: de muitas maneiras diferentes. Em outras palavras, não existe apenas uma cultura popular, mas várias. E é justamente esta diversidade inerente à cultura popular que serve de ponto de partida para o estudo de Mita sobre as canções populares. O interesse de Mita por este tema está na enorme variedade de sentidos que as canções populares incorporam por trás das convenções do gênero (Mita, 2012a, p. 5-7).

Esta diversidade pode ser vista por vários ângulos. Por exemplo, Mita destaca que existem no mínimo duas formas bastante distintas, mas igualmente "populares", de canções: o minyô e o ryûkôka. O minyô é, em princípio, aquela canção que surge espontaneamente numa comunidade ou numa região particular. Sua letra trata das características específicas daquele local, e ela é transmitida de geração em geração entre os moradores daquela região. O ryûkôka, por sua vez, não surge como uma expressão direta do povo. Ele é muitas vezes produzido por artistas profissionais e especialistas interessados em sucesso financeiro, sem a preocupação de refletir um contexto regional específico. Uma vez finalizado, porém, o ryûkôka é distribuído tendo em vista as camadas populares, e, justamente por ser algo consciente e planejado, sua distribuição não se limita, como no minyô, a uma comunidade local, alcançando assim um público muito maior. Em compensação, o ryûkôka costuma sair logo de moda e ser esquecido, tendo uma vida mais curta do que o minyô (Mita, 2012a, 189-190).

Simplificando bastante o argumento, o minyô seria a canção feita pelo povo e para o povo. O ryûkôka, por outro lado, seria a canção feita não necessariamente pelo povo, mas apenas para ele. O próprio Mita ressalta que a fronteira entre esses dois tipos de canção nem sempre é clara, e que se trata apenas de categorias analíticas. Seja como for, a classificação é útil para delimitar o interesse de Mita, que, mais do que o minyô, volta-se principalmente para o ryûkôka e como ele se desenvolveu no Japão (sobre a justificativa para esta escolha, ver Mita, 2012a, p. 8-10). Uma vantagem desta ênfase no ryûkôka é que, justamente por não se limitar a uma região específica, ele permite investigar a atitude popular no Japão em termos mais amplos. Embora esta atitude venha sempre filtrada pelo olhar dos empreendedores e artistas que produzem as canções, sua recepção mais difusa junto à população significa que se trata de um fenômeno abrangente.

Porém, Mita deixa claro que dentro do próprio gênero do ryûkôka há novamente uma grande diversidade, ou seja, há diferentes maneiras de produzir canções para o povo. Mita destaca principalmente como as características gerais dos ryûkôka passaram por profundas transformações ao longo do tempo. Grande parte do trabalho de Mita consiste em encontrar uma lógica e um sentido mais geral nesse processo de mudança. Para isso, Mita adota um ponto de vista histórico, analisando, como já mencionado, a evolução dos ryûkôka desde 1868 até a década de 1960. 
Podemos ver, portanto, que o ponto de partida do trabalho de Mita é enfatizar a diversidade e a mutabilidade da cultura popular. Não existe uma cultura popular japonesa única. Neste sentido, sua posição é em princípio avessa a essencialismos. É preciso, no entanto, examinar mais concretamente quais os conceitos que ele utiliza em sua perspectiva histórica, e verificar se eles podem ser relevantes não apenas para entender canções populares, mas também outras manifestações culturais.

\section{Urbanização}

Mita reúne as letras das canções que mais fizeram sucesso no Japão desde o começo do período Meiji e a partir disso identifica quais os temas predominantes em cada canção, tomando por base uma relação de dez temas possíveis, todos eles definidos por ele mesmo e um grupo de colaboradores: raiva, tristeza, alegria, afeto, heroísmo, apego, humor, solidão, nostalgia/fascínio, transitoriedade. Ele analisa então como esses temas foram mudando ao longo dos anos. Mita é muito criticado neste ponto, porque o critério adotado para a definição dos temas e a classificação das canções segundo tais temas nunca fica muito claro, abrindo margem para a arbitrariedade (e.g. Fujii, 1999).

A crítica é certamente válida, mas, apesar dessa limitação, creio que as intepretações de Mita e o esquema teórico subjacente a elas permanecem relevantes. Neste sentido, não interessa tanto questionar sobre os critérios que levaram Mita a escolher este ou aquele tema em particular. $\mathrm{O}$ mais importante é indagar sobre a lógica mais geral por trás do modo como ele trabalha com esses temas.

Como foi dito, Mita enfatiza principalmente a questão da mudança nos temas das canções. Uma primeira mudança evidente é que certos temas se tornam mais frequentes, enquanto outros desaparecem. O tema da "raiva", por exemplo, que já é raro no começo de Meiji, acaba diminuindo ainda mais, eventualmente sumindo das canções (Mita, 2012a, p. 15). O tema da "tristeza", por outro lado, apresenta um crescimento constante (Mita, 2012a, p. 44). Mas não é tanto esta mudança quantitativa que interessa a Mita. A mera frequência dos temas não diz nada muito significativo (Mita, 2012a, p. 15). Alguém poderia se sentir tentado a concluir apressadamente que a maior frequência do tema da "tristeza", por exemplo, seria indício de que este sentimento teria se tornado mais comum entre a população, mas não é este o argumento de Mita.

Para ele o que realmente importa é a mudança qualitativa dos temas, ou seja, independentemente da frequência com que os vários temas aparecem, o sentido de cada um deles muda profundamente ao longo dos anos. Assim, o tipo de raiva ou o tipo de tristeza que surge nas canções no começo do período Meiji é muito diferente do tipo de raiva e de tristeza que aparecem nas canções da década de 1920 ou de 1940.

Não tenho como expor em detalhes as considerações de Mita sobre cada tema, mas o que convém enfatizar é que Mita sugere que há uma tendência comum em todos esses casos: nas canções mais antigas, a raiva, a tristeza, a alegria ou a solidão são descritas do ponto de vista de quem vive no meio rural - nas vilas, ou no chamado 
inaka -, enquanto nas canções mais recentes o ponto de vista passa a ser o de quem vive nas cidades, principalmente em Tóquio. Para ficar em apenas um exemplo, entre 1868 e o começo do século XX, o tema da solidão aparece nas canções como algo inerente à cidade e ao ambiente de Tóquio, o que reflete o ponto de vista de quem tem suas raízes no mundo das vilas e para quem a cidade é ainda um terreno estranho e até mesmo hostil. Depois da Segunda Guerra Mundial, porém, são as vilas que passam a ser associadas com o tema da solidão, enquanto as cidades passam a ser retratadas como lugares dinâmicos onde as pessoas podem se encontrar umas com as outras e crescer juntas, revelando uma perspectiva de quem agora se sente confortável no meio urbano (Mita, 2012a, p. 174-182).

Esta mesma tensão entre o rural e o urbano aparece em vários outros temas examinados por Mita: raiva, tristeza, alegria, etc. E também nestes casos há a transição de uma perspectiva que idealiza o mundo rural para uma perspectiva que idealiza o mundo urbano. Do ponto de vista analítico, portanto, há um conceito mais amplo de urbanização unificando os diversos processos de mudança qualitativa que Mita identifica nos temas das canções.

Mita sugere em vários momentos que isso de deve ao fato de a própria sociedade japonesa ter efetivamente assistido, principalmente a partir da década de 1920, a crescentes ondas migratórias de pessoas deixando suas vilas para tentar a sorte nas cidades, especialmente na capital, Tóquio (Mita, 2012a, p.186-188; ver também Harootunian, 2000). As mudanças nas letras das canções refletiriam assim as mudanças nas condições sociais do Japão.

A ideia de urbanização atua, portanto, como conceito central na articulação entre a dinâmica das manifestações culturais e a realidade social em que elas se desenvolvem. Este conceito permite, ademais, que examinemos esta realidade social de maneira mais precisa. Ao invés de trabalhar com generalizações sobre a sociedade japonesa, o esquema de Mita se concentra num aspecto particular bem definido desta sociedade: as relações entre o meio rural e o meio urbano. É esta questão mais específica que serve de referência para interpretar a cultura popular e suas transformações.

\section{Diferença geracional}

Surge aqui uma dificuldade: se a questão da urbanização é de fato tão importante, não seria possível retomar as tentativas mencionadas anteriormente de encontrar as raízes da cultura popular atual na cultura de Edo? Trata-se, afinal, de uma cultura também urbana, própria dos comerciantes que viviam na antiga Tóquio. Não poderíamos assim considerar o processo de urbanização descrito por Mita simplesmente como a difusão de um padrão que já existia desde o período Edo, mas que somente a partir do século XX teria se expandido por todo o território japonês?

Se seguirmos a lógica do esquema de Mita, a resposta deve ser negativa. Isso porque, assim como não existe apenas uma cultura popular, mas várias, e assim 
como não existe um tipo de ryûkôka, mas vários, existem também diferentes tipo de cultura urbana.

Embora a questão não seja examinada a fundo em Kindai Nihon no Shinjô no Rekishi, Mita tem plena consciência do problema e em trabalhos posteriores continuou a investigar a ideia de cidade, enfatizando justamente a enorme diversidade de experiências que o meio urbano oferece ao longo do tempo e para diferentes grupos de pessoas. A cidade assume, portanto, uma grande variedade de sentidos: entusiasmo, frustração, violência, intimidade, criminalidade, etc. (Mita, 2011a; 2011b). Neste sentido, igualar a experiência urbana do período Edo com a experiência urbana do século XX seria pouco razoável.

No entanto, diferentemente de Kindai Nihon no Shinjô no Rekishi, nesses estudos Mita tende a tratar de canções e outras formas de cultura popular de maneira menos aprofundada, preferindo refletir sobre a complexidade do processo de urbanização a partir de outros aspectos. Para os propósitos deste artigo, uma análise mais clara sobre a relação entre a diversidade da experiência urbana e a evolução da cultura popular pode ser encontrada no trabalho dos discípulos de Mita, muitos dos quais figuram hoje entre os principais nomes na teoria social japonesa: Shunya Yoshimi, Shinji Miyadai, Masachi Ohsawa, Ryuzo Uchida. Estes autores demonstram ter sido fortemente influenciados por Mita, mas ao mesmo tempo têm proposto reformulações importantes e originais, além de incluir em suas reflexões os problemas e desafios do contexto atual. Suas contribuições são, por isso, fundamentais para compreender como a relação entre urbanização e cultura popular pode ser tratada de maneira mais nuançada.

O exemplo mais representativo neste sentido é o livro já clássico de Shunya Yoshimi (1987), Toshi no Doramaturugii, em que ele discute a própria formação da cidade de Tóquio a partir de suas regiões de diversão e entretenimento, ou seja, os locais onde se concentram os principais teatros, cinemas, lojas, bares, festivais e outras atrações populares (a expressão em japonês é sakariba). Novamente, trata-se de um trabalho que não discute as formas de cultura popular mais em voga atualmente como anime ou manga, mas, assim como no caso de Mita, veremos que a contribuição teórica de Yoshimi pode nos ajudar a compreender também estas formas.

É significativo que, assim como Mita, Yoshimi também enfatiza a diversidade e a mutabilidade das práticas culturais e adota por isso uma perspectiva histórica que neste caso parte do final do período Edo e vai até a década de 1980. A ideia básica do livro de Yoshimi é que, ao longo deste período, diferentes regiões de Tóquio exerceram a função de sakariba. Em linhas gerais, é possível identificar a seguinte transição: o principal sakariba de Tóquio no final do período Edo se encontra na região de Asakusa, mas passa para Ginza no começo do século XX, depois para Shinjuku com o fim da Segunda Guerra Mundial, e finalmente muda para Shibuya na década de 1970. Cada um desses sakariba teria suas próprias práticas e valores, de modo que a experiência urbana de Tóquio aparece no trabalho de Yoshimi como um fenômeno extremamente diverso e dinâmico. 
Mas ele não se contenta apenas em apontar para esta transição de uma região para outra. Assim como Mita no caso das mudanças nas canções populares, Yoshimi procura formular conceitos que nos permitam encontrar uma lógica geral na mudança de um sakariba para outro. A interpretação de Yoshimi é complexa e inclui diversos fatores, mas para os propósitos deste artigo creio ser possível destacar um conceito em particular: a diferença geracional.

A importância da questão geracional surge primeiramente na transição de Asakusa para Ginza, no início do século XX. Na concepção de Yoshimi, o que caracterizava Ginza como um centro de entretenimento nessa época era o alto grau de interferência por parte das elites políticas e econômicas na formação da região. Diferentemente de Asakusa, onde as lojas, os teatros, os cinemas e os festivais estavam em geral nas mãos da própria população local e seguiam os valores e os hábitos das classes populares, acostumadas com barulho, com rompantes espontâneos e com certo nível de contato corporal, as lojas e as exposições em Ginza seguiam o protocolo traçado pelos órgãos do governo e pelos grandes empresários, que procuravam justamente educar as massas a adotar um comportamento mais comedido e supostamente mais compatível com o ideal de civilização associado à modernidade ocidental que as elites da época procuravam seguir. Justamente devido a esta conotação pedagógica, o principal público alvo de Ginza eram os jovens, algo que não acontecia em Asakusa (Yoshimi, 1987, p. 246-266).

Com isso, a caracterização da cultura popular, que Mita já havia associado ao espaço especificamente urbano, ganha com Yoshimi uma camada adicional: ela se torna um fenômeno próprio das gerações mais jovens. Este é um aspecto que, segundo Yoshimi, vai persistir nas épocas posteriores, embora, como seria de esperar, de maneiras diferentes.

Na transição de Ginza para Shinjuku após a Segunda Guerra Mundial, por exemplo, os jovens continuam sendo os principais atores, mas desaparece aquela função pedagógica de assimilação dos valores aceitáveis às elites. Os jovens que passam a transitar e divertir-se em Shinjuku são principalmente estudantes universitários muito mais críticos ao discurso das elites e das autoridades. Trata-se, afinal, do ápice dos movimentos estudantis e da influência de ideologias socialistas e liberais. Muitos inclusive utilizam os bares, cinemas, concertos musicais e lojas da região como locais de reunião e mobilização política. Os jovens de Shinjuku utilizam assim o espaço urbano e a cultura popular como meio de protesto e resistência (Yoshimi, 1987, p. 277-287).

Já na transição de Shinjuku para Shibuya na década de 1970, embora os jovens sejam ainda o principal público alvo, há uma fragmentação do senso de comunidade que podia ser visto no caso de Shinjuku. É a época em que os jovens se afastam dos movimentos estudantis, seja pela falta de resultados concretos, ou então pela violência excessiva que alguns desses movimentos acabam cometendo. Shibuya passa a refletir essa tendência, em que predomina a ênfase em formas de consumo e de entretenimento de cunho mais individualista. Além disso, Shibuya assume uma estrutura mais segmentada, com lojas e casas de espetáculo voltadas para diferentes gostos e estilos, 
sem que haja uma interação entre os vários setores. Os jovens que passam a frequentar Shibuya perdem assim o interesse em ações coletivas e projetos políticos, e a cultura popular se torna reflexo de apatia e incomunicabilidade (Yoshimi, 1987, p. 305-319; ver também Kitada, 2002).

Dessa forma, ao chamar nossa atenção para mudanças nas experiências específicas das camadas mais jovens, o conceito de diferença geracional permite esclarecer melhor os diferentes sentidos que a relação entre o meio urbano e a cultura popular assume ao longo do tempo. No caso de Ginza, a cultura popular e a cidade atuam como instrumentos de manipulação e socialização dos jovens; em Shinjuku, os jovens resistem a essa tendência e assumem o controle da cidade e das manifestações culturais; em Shibuya, o senso de comunidade se esvai, de modo que a cidade e a cultura se fragmentam em segmentos relativamente isolados.

\section{Urbanização e diferença geracional na evolução do manga}

A ênfase de Mita e Yoshimi na questão da mudança e da diversidade das formas culturais - seja no caso das canções populares ou dos sakariba - contribuem para tratar da questão da cultura popular sem negligenciar a historicidade e a complexidade de suas condições sociais. Além disso, a especificação da questão cultural como algo que está diretamente ligado 1) ao processo de urbanização do Japão e 2) às experiências das gerações mais jovens oferece conceitos que nos permitem tratar da questão de maneira mais precisa, sem cair em generalizações essencialistas sobre a cultura japonesa.

No entanto, vimos que Mita e Yoshimi não falam sobre os temas que hoje dominam o debate sobre a cultura popular japonesa, como o anime e o manga. Sugeri acima que, apesar disso, suas ideias podem nos ajudar também a entender essas formas atualmente em voga, e nesta seção irei discutir este ponto. Para isso, tomarei como referência o trabalho de Shinji Miyadai, outro discípulo de Munesuke Mita de grande influência no cenário intelectual japonês atual. Uma de suas obras mais importantes é o livro Sabukaruchaa Shinwa Kaitai, escrito por Miyadai com outros colaboradores (1993), mas cuja perspectiva teórica é definida claramente por ele. O livro é relevante para este artigo por tratar justamente de temas como manga, em parte com base nos conceitos discutidos acima de urbanização e diferença geracional.

Assim como Mita e Yoshimi, Miyadai e seus colegas também adotam uma perspectiva histórica que ressalta a diversidade e a mutabilidade do manga. Neste caso, eles partem do período Meiji e vão até a década de 1980.

Segundo Miyadai e seus colegas, um momento crucial para a cultura popular japonesa se dá no período de transição do século XIX para o século XX, justamente quando ocorre a expansão das camadas urbanas e dos divertimentos populares nas cidades. A urbanização é, portanto, novamente o ponto de partida. E uma das consequências desse processo é a crescente ansiedade sobre como ensinar as gerações mais jovens a se comportar adequadamente no novo ambiente urbano, o que acaba sendo 
incorporado pela cultura popular. Isso pode ser visto nos chamados shônen shôsetsu e shôjo shôsetsu da época, romances sobre aventuras e histórias amorosas centradas em protagonistas jovens. Neles, o menino ou a menina são expostos a uma série de desafios até que no final eles conseguem superar as dificuldades e restaurar a ordem das coisas. $\mathrm{O}$ que é característico desse tipo de literatura é que a ordem natural das coisas é no fundo a ordem dos adultos que fazem parte das elites urbanas: o menino resolve crimes e outros comportamentos antissociais; a menina consegue se casar (Miyadai; Ishihara; Otsuka, 1993, p. 26-28). Há, portanto, uma função pedagógica nesses romances, voltados a educar a juventude diante dos perigos da cidade de uma forma análoga ao que Yoshimi descreve no sakariba de Ginza.

No entanto, a popularidade deste tipo de literatura passa a ser eclipsada nas décadas de 1940-50 pelo manga. Segundo Miyadai e seus colegas, a crescente popularidade do manga nesta época, tanto entre o público masculino como feminino, se deve em grande parte à influência de Osamu Tezuka, que, ao importar um estilo cinematográfico para a composição dos quadrinhos, ajudou a tornar o manga um meio mais sofisticado e capaz de atrair um público maior. No entanto, o conteúdo dos manga continua reproduzindo inicialmente as mesmas histórias moralizantes dos shônen e shôjo shôsetsu, em que o protagonista jovem aparece como receptor passivo dos valores aceitos pelas figuras de autoridade (Miyadai; Ishihara; Otsuka, 1993, p. 265-266).

Já na década de 1950, porém, Miyadai e seus colaboradores apontam uma ruptura não apenas no manga, mas no meio urbano japonês em geral. Surge um discurso cultural em que a figura do jovem se torna independente dos valores dos adultos. Romances, filmes e canções passam a retratar o jovem como oprimido e inconformado com as expectativas dos mais velhos. O jovem passa a ter valores e aspirações que os adultos não compreendem. O livro Taiyô no Kisetsu, publicado por Shintaro Ishihara em 1955, é um exemplo frequentemente citado dessa tendência. Da mesma forma, ídolos como James Dean e Yujiro Ishihara passam a simbolizar também esta nova imagem de juventude rebelde (Miyadai; Ishihara; Otsuka, 1993, p. 28-31).

No manga, esta atitude de resistência começa a aparecer no trabalho do próprio Osamu Tezuka, que passa a incluir em suas obras um conteúdo maior de crítica social. No caso do manga masculino, essa tendência se torna ainda mais evidente nos gekiga, historias de teor mais violento e sóbrio que fazem grande sucesso a partir da década de 1960. Miyadai e seus colaboradores notam que muitas dessas histórias retratam um jovem de origem pobre que vem do interior para a cidade grande realizar algum objetivo antissocial: vingança, ou uma vida de crime. O processo de transição para o meio urbano continua, portanto, estruturando a narrativa, e o protagonista continua sendo um jovem, mas, diferentemente dos shônen shôsetsu, este jovem já não precisa mais se adequar aos padrões tidos como respeitáveis (Miyadai, Ishihara, Otsuka, 1993, p. 268-281). No manga feminino é possível verificar algo análogo, embora a maioria trate de histórias 
de amor. Miyadai e seus colegas destacam, por exemplo, a presença de protagonistas femininas jovens sexualmente ativas, o que gera uma tensão entre a atitude da jovem e a expectativa da sociedade dominante (Miyadai; Ishihara; Otsuka, 1993, p. 103-111).

Esta cultura de resistência é evidentemente próxima da atitude dos jovens em Shinjuku descrita por Yoshimi. O manga reflete assim a atitude da juventude da época. Da mesma forma, assim como o enfraquecimento desses movimentos jovens na década de 1970 levou à formação de um novo sakariba em Shibuya, ele vai trazer também mudanças para as características do manga a partir desse período.

Com o fim da atmosfera de mobilização política e de protesto, o foco da atenção deixa a esfera pública e passa a se voltar cada vez mais para o mundo interior do indivíduo. Essa mudança se faz sentir também no manga. No período anterior, o manga se concentrava nas ações dos protagonistas: vingança, luta. A partir dos anos de 1970, por outro lado, vão se tornar mais frequentes as histórias que privilegiam os pensamentos e as inseguranças internas das personagens (Miyadai; Ishihara; Otsuka, 1993, p. 31-32).

Miyadai e seus colaboradores enfatizam que esta mudança se fez sentir mais cedo no manga feminino. As histórias continuam retratando histórias de amor, mas as protagonistas passam a se mostrar mais inseguras, questionando constantemente o próprio valor, mesmo quando algum rapaz se mostra atraído por elas. Uma característica desse tipo de manga é a grande quantidade de monólogos interiores, em que essas dúvidas ganham livre expressão (Miyadai; Ishihara; Otsuka, 1993, p. 111-115). No manga masculino, algo parecido aparece um pouco mais tarde, no final da década de 1970. Segundo Miyadai, isto pode ser visto especialmente no sucesso de histórias de amor escritas para o público masculino dessa época. Uma diferença com relação ao manga feminino neste caso é a presença maior de triângulos amorosos e infidelidades na trama. Mas mesmo assim essas histórias demonstram clara influência do manga feminino, empregando inclusive monólogos interiores para retratar os questionamentos interiores de personagens inseguros (Miyadai; Ishihara; Otsuka, 1993, p. 300-309).

Porém, apesar das incertezas de seus protagonistas, esses manga acabam no final resolvendo, de maneira muitas vezes simplista, os dilemas amorosos de suas tramas. No caso do manga feminino um recurso comum é introduzir uma figura masculina que aceita a protagonista pelo que ela é, incondicionalmente (Miyadai; Ishihara; Otsuka, 1993, p. 115). No caso do manga masculino, a solução para os triângulos amorosos e as infidelidades é postular que a amizade dos personagens é simplesmente inabalável, de modo que no final todos encontram o seu par, sem que a harmonia do grupo seja posta em perigo (Miyadai; Ishihara; Otsuka, 1993, p. 312-314).

Miyadai e seus colegas interpretam essas soluções fáceis como uma idealização criada para lidar, ao menos no mundo da ficção, com a incomunicabilidade e ansiedade que na realidade caracterizavam a juventude da década de 1970. Esse tipo de final feliz ofereceria algum tipo de conforto simbólico para que as pessoas pudessem suportar a 
tensão da vida real. No entanto, os autores salientam que, mais ou menos no mesmo período, começam a surgir também outros tipos de manga que adotam uma estratégia muito diferente. Ao invés de tentar domesticar a realidade fragmentada da época, eles oferecem uma fuga dessa realidade.

Isso ocorre principalmente em histórias de ficção científica, o que parece natural, já que é um gênero que costuma retratar mundos distantes e exóticos. Mas o tipo de ficção científica que começa a se popularizar entre os anos de 1970-80 assume um perfil novo. Tradicionalmente, o manga de ficção científica costumava retratar heróis e suas aventuras, muitas vezes com o mesmo tom moralizante dos antigos shônen shôsetsu. Esse tipo de narrativa heroica no fundo pressupõe uma função educadora, de encorajar e preparar o leitor para lidar com a realidade. Porém, no novo tipo de ficção científica que surge no fim dos anos de 1970, embora a trama se passe no espaço sideral ou num mundo pós-apocalíptico, os personagens tendem a ser triviais e suas ações até mesmo tediosas, não havendo mais feitos heroicos. É claro que há uma variação muito grande, mas nos casos mais extremos não há nenhuma causa pela qual lutar, nenhum herói com a missão de salvar o mundo, nenhuma equipe de amigos inseparáveis, nenhum vilão a derrotar. Não se espera tampouco que a história tenha um efeito catártico sobre o leitor (Miyadai; Ishihara; Otsuka, 1993, p. 325-349).

Qual seria então o atrativo desse tipo de história? Segundo Miyadai e seus colaboradores, o interesse do leitor estaria em encontrar apenas um cenário, ou seja, um mundo aparte, com sua própria lógica interna, seus reinos, suas leis, seus valores, suas máquinas, seus rituais, etc. Os personagens, seja do ponto de vista de suas ações ou de sua interioridade, seriam algo secundário. Essa tendência pode ser vista mais claramente no caso de séries ou franquias, como, por exemplo, a série Gundam, em que há uma infinidade de histórias independentes de guerra espacial com diferentes personagens, todos eles ocupando o mesmo universo fictício. Mesmo quando as ações dos personagens são heroicas, eles se tornam tão estereotipados e repetitivos que acabam se tornando secundários em relação ao mundo em que eles habitam, este sim o verdadeiro centro das atenções (Azuma, 2001).

Evidentemente, seria impossível que esses mundos fictícios não buscassem inspiração no mundo real, mas ao se concentrar não tanto nos personagens ou no drama humano, mas apenas no cenário de fundo, essas obras dão aos leitores a impressão de constituir um universo autônomo e separado, possibilitando dessa forma uma fuga mais efetiva da realidade. Os leitores desse tipo de história passam então a se tornar obcecados em colecionar a maior quantidade de informação possível sobre os menores detalhes a respeito desse mundo aparte. Quanto mais detalhes, mais fácil se torna a imersão.

Os leitores aficionados deste tipo de manga são para Miyadai e seus colegas a origem dos fãs otaku, que, longe de serem herdeiros da cultura do período Edo, surgem como uma reação bastante específica ao contexto de fragmentação da cultura jovem e do espaço urbano do Japão nas décadas de 1970 e 80. 


\section{Limitações}

Em linhas gerais, a análise de Miyadai sobre a evolução do manga é compatível com o esboço teórico que procurei traçar a partir de elementos dos estudos de Mita e Yoshimi, especialmente no que diz respeito aos dois conceitos de urbanização e diferença geracional. As mudanças no manga estão diretamente relacionadas à experiência da cidade no século XX e também à identidade especificamente jovem que se forma e se transforma dentro deste contexto urbano. Assim como no caso das canções em Mita e do sakariba em Yoshimi, estes dois conceitos permitem também interpretar a diversidade e a mutabilidade do manga de maneira mais concreta.

Porém, como mencionei anteriormente, este esquema tem também suas limitações. Uma dificuldade especialmente séria diz respeito a alguns pressupostos presentes no conceito de urbanização desenvolvido por Mita e seus discípulos.

Eles tendem a utilizar o conceito de urbanização em termos evolucionistas, como uma sucessão ordenada de fases históricas bem definidas. Antes do período Meiji, o Japão seria uma sociedade predominantemente rural; depois do período Meiji e principalmente a partir da década de 1920 ele teria se tornado uma sociedade urbana. A rigor, não se trata de uma visão específica a Mita e seus discípulos. Pelo contrário, este tipo entendimento é bastante comum tanto entre intelectuais como entre o público em geral.

O problema é que ele vem sendo há décadas criticado e revisto pela historiografia japonesa. O historiador Yoshihiko Amino é talvez o representante mais conhecido dessa crítica, já que seus trabalhos têm grande repercussão não apenas entre historiadores, mas nas ciências sociais e humanidades em geral. Amino se esforçou em demolir esta narrativa evolucionista de que só depois de Meiji o Japão teria se transformado numa sociedade urbana. Segundo ele, esta imagem se popularizou em grande parte porque a administração e a tributação antes de Meiji de fato se interessavam mais pela produção agrícola. Por causa de sua importância administrativa, a documentação da produção agrícola foi mais amplamente preservada, dando a impressão de que a sociedade japonesa como um todo era agrícola e rural. No entanto, investigando documentos muitas vezes negligenciados pelas autoridades oficiais, Amino argumenta que diversas regiões tradicionalmente tidas como rurais tinham na realidade suas economias baseadas em comércio e manufaturas, constituindo autênticas cidades. A fronteira entre vila e cidade seria, portanto, muito mais fluida do que se costuma retratar (Amino, 2005).

Esta fluidez, ademais, não se restringe apenas ao passado. Como um importante grupo de antropólogos vem enfatizando, a interação entre o mundo da vila e o mundo da cidade continua sendo ainda hoje uma questão fundamental, com resultados complexos, imprevisíveis e mesmo contraditórios (Furukawa, 2007; Matsuda, 2009). Os trabalhos de Mita e seus seguidores, porém, têm dificuldade de lidar com estas questões, justamente por pressupor uma ruptura radical entre as duas esferas. 
Isso não significa que o conceito de urbanização deva ser abandonado. $\mathrm{O}$ que se faz necessário é uma interpretação mais elaborada do conceito que permita apreender a particularidade da experiência urbana não tanto como algo que surge em substituição à realidade da vila, mas como um fenômeno que se forma e se transforma em constante interação com ela.

\section{Conclusão}

Neste trabalho, procurei identificar na literatura sociológica japonesa conceitos que nos permitissem analisar a questão da cultura popular a partir da diversidade e historicidade de suas condições sociais. Tomando como base os trabalhos de Munesuke Mita, Shunya Yoshimi e Shinji Miyadai, sugeri que dois conceitos em particular merecem especial atenção: urbanização e diferença geracional. Esta ênfase no papel específico da experiência urbana e das gerações mais jovens na formação da cultura popular possibilita uma discussão mais precisa e concreta das mudanças no contexto da sociedade japonesa e suas repercussões culturais.

Finalmente, salientei que, apesar de sua importância, esta perspectiva teórica tem também suas limitações, principalmente no que diz respeito ao teor evolucionista e simplista com que a noção de urbanização é por vezes articulada. Porém, argumentei que isso não invalida o esquema proposto neste trabalho. $\mathrm{O}$ que esta limitação sugere é a necessidade de aprofundar nossa reflexão a fim de encontrar interpretações mais elaboradas sobre a influência da urbanização e da diferença geracional sobre as manifestações da cultura popular.

\section{Referências bibliográficas}

AMINO, Yoshihiko. Nihon no Rekishi o Yominaosu. Tóquio: Chikuma, 2005.

AZUMA, Hiroki. Dôbutsuka Suru Posutomodan. Tóquio: Kodansha, 2001.

BESTOR, Victoria; BESTOR, Theodore C.; YAMAGATA, Akiko (org.). Routledge Handbook of Japanese Culture and Society. Abingdon: Routledge, 2011.

FUJII, Hidetada. Mita Munesuke Gendai Nihon no Shinjô no Rekishi. In: TSUTSUI, Kiyotada (org.). Nihon no Rekishi Shakaigaku. Tóquio: Iwanami, 1999. Capítulo 12, p. 207-218.

FURUKAWA, Akira. Village Life in Modern Japan. Melbourne: Trans Pacific Press, 2007.

HAROOTUNIAN, Harry. Overcome by Modernity: History, Culture, and Community in Interwar Japan. Princeton: Princeton University Press, 2000.

HAROOTUNIAN, Harry; YODA, Tomiko (org.). Japan after Japan: Social and Cultural Life from the Recessionary 1990s to the Present. Durham: Duke University Press, 2006.

IWABUCHI, Koichi. "Soft" Nationalism and Narcissism: Japanese Popular Culture Goes Global. Asian Studies Review, Melbourne, v. 26, n. 4, p. 447-469, dezembro, 2002. 
IWABUCHI, Koichi. Undoing Inter-national Fandom in the Age of Brand Nationalism. Mechademia, Minneapolis, v. 5, n. 1, p. 87-96, novembro, 2010.

KAWANO, Satsuki; ROBERTS, Glenda S.; LONG, Susan Orpett (org.). Capturing Contemporary Japan: Differentiation and Uncertainty. Honolulu: University of Hawaii Press, 2014.

KITADA, Akihiro. Kôkoku Toshi Tôkyô. Tóquio: Kosaido, 2002.

LAM, Peng Er. Japan's Quest for Soft Power: Attraction and Limitation. East Asia, Durham, v. 24, n. 4, p. 349-363, dezembro, 2007.

MATSUDA, Motoji. Nichijô Jinruigaku Sengen. Kyoto: Sekaishisosha, 2009.

MILLER, Laura. Cute Masquerade and the Pimping of Japan. International Journal of Japanese Sociology, Tóquio, v. 20, n. 1, p. 18-29, novembro, 2011.

MITA, Munesuke. Manazashi no Jigoku. Tóquio: Iwanami, 2011a (Mita Munesuke Chosakushû VI).

MITA, Munesuke. Atarashii Bôkyô no Uta. Tóquio: Iwanami, 2011b (Mita Munesuke Chosakushû VI).

MITA, Munesuke. Kindai Nihon no Shinjô no Rekishi: Ryûkôka no Shakai Shinrishi. Tóquio: Iwanami, 2012a (Mita Munesuke Chosakushû IV).

MITA, Munesuke. Meiji Ishin no Shakai Shinrigaku. Tóquio: Iwanami, 2012b (Mita Munesuke Chosakushû III).

MIYADAI, Shinji; ISHIHARA, Hideki; OTSUKA, Meiko. Sabukaruchaa Shinwa Kaitai, Tóquio: Parco Shuppankyoku, 1993.

OKUNO, Takuji. Roots of Cool Japan: From the Japanese Traditional Edo Culture to Anime and Manga. Kwansei Gakuin University Social Sciences Review, Nishinomiya, v. 19, n. 1, p. 1-7, março, 2014.

OKUNO, Takuji. Japan Kuuru to Edo Bunka. Tóquio: Iwanami, 2015.

WATANABE, Yasushi; MCCONNELL, David (org.). Soft Power Superpowers: Cultural and National Assets of Japan and the United States. Armonk: M.E. Sharpe, 2008.

YOSHIMI, Shunya. Toshi no Doramaturugii. Tóquio: Koubundou, 1987. 